Caligrama, Belo Horizonte, v. 23, n. 1, p. 67-78, 2018

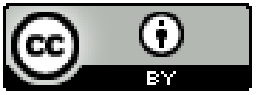

\title{
Percursos pós-modernistas: hibridismo e simulação na ficção de Luiz Ruffato
}

\section{Postmodernist paths: Hybridism and Simulation in the Fiction of Luiz Ruffato}

Maurício Silva

Universidade Nove de Julho, São Paulo, São Paulo / Brasil

maurisil@gmail.com

Resumo: O presente trabalho tem como objetivo analisar a prosa de ficção de Luiz Ruffato - em especial seu livro Flores artificiais (2014) sob a perspectiva do hibridismo (considerando, em especial, o conceito de hibridismo identitário, proposto por Stuart Hall) e da simulação (considerando, em especial, o conceito de simulacro, proposto por Jean Baudrillard). A intenção deste artigo é demonstrar como a prosa de ficção de Luiz Ruffato incorpora, no plano da narrativa, mas também no da linguagem, ambos os conceitos acima aludidos, fazendo deles categorias estruturantes de sua produção ficcional.

Palavras-chave: Luiz Ruffato; literatura brasileira; hibridismo; simulação; pós-modernidade.

Abstract: This article aims to analyze the Luiz Ruffato fiction especially his book Flores Artificiais (2014) - under the hybrid approach (considering in particular the concept of hybridity identity proposed by Stuart Hall) and simulation (considering in particular the concept of simulacrum, proposed by Jean Baudrillard). This article intents to demonstrate how to Luiz Ruffato prose fiction incorporates both concepts alluded above into the narrative plan, and also in language, making them structuring categories of his fictional production.

Keywords: Luiz Ruffato; Brazilian literature; hybridity; simulation; post-modernity. 


\section{Introdução}

A produção literária brasileira exprime, atualmente, as injunções de uma contemporaneidade marcada pela diversidade cultural, um dilema - entre muitos outros que fazem dela uma expressão caleidoscópica que a constrange a assumir, de início, pelo menos duas atitudes críticas: a urgência de uma revisão ampla de paradigmas estéticos que dão sustentação à atividade literária, estabelecendo novos protocolos de apropriação, interpretação e reorganização da produção ficcional, e a imposição de um deslocamento epistemológico que passa do foro textual como centro do discurso estético para a consideração de outras instâncias conformadoras e legitimadoras da obra literária. Trata-se, em outros termos, de uma tentativa de ultrapassar os limites regidos pela natureza endógena da produção literária e da concepção de gênero discursivo para uma perspectiva exógena, em que elementos como o leitor, os meios de comunicação, as condições sociais de produção do texto ficcional etc. adquirem validade plena no âmbito da cultura contemporânea.

Essa aproximação entre um fazer literário específico da literatura brasileira com um movimento mais amplo de reconfiguração da geopolítica cultural na contemporaneidade, como sugere Canclini (2012), leva à necessidade de transformações que se fundamentam em conceitos como os de hibridismo e simulação, para ficarmos apenas nas mais evidentes categorias que perfazem um amplo universo de concepções simbólicas e epistêmicas responsáveis pela constituição do mundo atual. No âmbito do texto literário, tais transformações apontam para uma evidente diversidade de relações culturais e estéticas, em que conceitos como os de sujeito e centro - fundamentais para a constituição de um saber unidirecional e sintomáticos de uma Weltanschauung moderna - cedem espaço a noções mais operatórias, como as de multiculturalismo, hibridismo cultural, estudos pós-coloniais e outros, os quais procuram traduzir, mais de acordo com uma realidade múltipla, as formações culturais relacionadas a um mundo globalizado. De fato, se, como quer Jameson em seu estudo sobre a relação entre cultura e globalização, a própria esfera da cultura se expandiu, levando-a a um processo de reformulação (JAMESON, 2002), é mesmo preciso levar em consideração não apenas as transformações por que têm passado a atual produção ficcional no mundo, mas também as mais recentes mudanças que a produção literária brasileira apresenta ao leitor do presente. 
É sobretudo a partir da última quadra do século XX que a literatura brasileira incorpora, com maior ou menor grau de evidência, modos de representação da escrita literária relativos a esse amplo processo de diversificação estética, inscrevendo nossa produção numa nova vertente da expressão artística e procurando incorporar componentes centrais da narratividade contemporânea. Busca, assim, subverter as formas tradicionais de constituição da ficção tradicional (incluindo, aí, a literatura moderna), ao desconstruir a percepção unidirecional do homem e do mundo que está à sua volta e, consequentemente, instaurando o diverso, o oblíquo e o instável no âmbito da composição narrativa.

Essa condição estética tem muito a ver com o conceito de pósmodernismo/pós-modernidade, cuja definição, aliás, não é tarefa das mais fáceis, principalmente se levarmos em consideração o fato de que não há um consenso absoluto em relação ao termo, ora utilizado para indicar o momento cultural e social em que vivemos, numa perspectiva histórica, ora para assinalar tendências culturais presentes a partir da segunda metade do século passado, numa perspectiva estética. Com efeito, época particularmente marcada pelo império dos extremos (HOBSBAWM, 2001), o século XX caracterizou-se por uma profusão de acontecimentos socioculturais que fazem da ideia de modernidade um conceito relativamente ultrapassado: seja no âmbito social - com as Guerras Mundiais, a instauração e o colapso do socialismo, as lutas contra o racismo, o feminismo agregado à emancipação da mulher etc. -, seja no cultural - com as vanguardas estéticas do início do século, o desenvolvimento da indústria cinematográfica, o advento da cultura de massa etc. - , o fato é que, com o passar do tempo, cada vez mais se impôs uma revisão do alcance conceitual do modernismo, ensejando o aparecimento de novos protocolos de interpretação da realidade contemporânea.

A "ideia" de pós-modernismo surge, portanto, nesse momento de crise de valores e de modelos de interpretação do real, o que nos remete diretamente para uma crise da identidade, como sugerem alguns pensadores contemporâneos (HALL, 2005). Tais fenômenos têm relação direta com a prática da criação literária, estabelecendo laços incoercíveis com a cultura de modo geral e a literatura em particular. Instaura-se, a bem da verdade, uma dicotomia quase natural entre modernismo e pósmodernismo, na medida em que manifestações artísticas de ambas as tendências buscaram caminhos diversos - muitas vezes, antípodas - para 
representar o mundo à sua volta, apresentando, por isso mesmo, marcas distintivas peculiares. Jair Ferreira dos Santos (2006, p. 10) exemplifica, resumidamente, essa oposição, quando diz que "os modernistas complicaram a arte por levá-la demasiado a sério. Os pós-modernistas querem rir levianamente de tudo".

Contudo, esse universo marcado ora pelo pastiche, ora pelo satírico - que não dispensa nem as visões trágicas relacionadas à perda da aura mítica da arte, de um Walter Benjamin (1986), ou a dissolução da negatividade, de um Jean Baudrillard (1990) -, pressupõe também um desnorteamento fatal: o sujeito pós-moderno, que vive imerso numa sociedade de consumo, que testemunha produtos se transformarem em símbolos de poder e que, portanto, vive nos limites cada vez mais tênues entre o real e o virtual, fica fatalmente sem saber para onde caminhar...

Talvez seja essa uma das muitas contradições de fundo da pósmodernidade, e a literatura brasileira contemporânea tem sido pródiga em lidar com essa situação, incorporando a aludida noção de diversidade que, no plano estético, associa-se de perto à noção de ecletismo própria dos tempos atuais (HUTCHEON, 1991). Como sugerimos antes, os anos 80 afirmam-se, nesse contexto, como um marco, com autores como Rubem Fonseca, João Antônio, Antonio Callado, Inácio de Loyola Brandão, Sérgio Sant'Anna, Silviano Santiago e muitos outros. Do ponto de vista dos gêneros produzidos, o ecletismo pós-modernista começa a se impor ainda mais, com os romances-reportagens e as narrativas fantásticas ou com os textos-depoimentos e a poesia marginal (SÜSSEKIND, 2004). E é ainda em meados dos mesmos anos 80 que o panorama literário brasileiro se modifica no que diz respeito à profissionalização do escritor, quando então o mercado passa a determinar quais as direções que seriam tomadas pelas editoras, interferindo diretamente na produção ficcional do período (LUCAS, 1985) e tornando a dinâmica pós-modernista cada vez mais hegemônica na cultura literária brasileira.

Nesse complexo contexto estético, o romance contemporâneo emerge como uma das principais vozes da nova geração literária nacional, à qual não faltou a busca de novas propostas ficcionais, a partir de uma tradição que se forjou com os resquícios deixados por pelo menos duas gerações modernistas ao longo do século XX. Como sugere Flávio Carneiro (2005), o que se faz hoje no Brasil, ao contrário de uma continuação pura e simples da tradição modernista brasileira, está marcado pela busca de outros caminhos, com a literatura 
desempenhando um imprescindível papel de manutenção da memória coletiva da comunidade.

A diversidade, como dissemos, é a marca dessa geração, mesmo que seja possível delinear temas recorrentes em várias obras ou mesmo que se possa verificar a busca comum de uma linguagem "original". Aliada a ela, cumpre lembrar a importância, para a atual produção literária brasileira, do espaço urbano, como a promover mais um deslocamento - agora espacial - no âmbito da ficção contemporânea (PINTO, 2004). Há ainda, finalmente, outros elementos que, no âmbito específico da literatura, fazem da atual produção brasileira expressão inequívoca de certo modo-de-ser pós-modernista, como o experimentalismo, o emprego da intertextualidade, o ecletismo estilístico, o esgarçar das fronteiras entre a arte erudita e a popular (PROENÇA FILHO, 1995).

Grande parte desses elementos estéticos estão presentes - às vezes, de modo obsedante - na produção ficcional de Luiz Ruffato, cujo romance Flores artificiais (2014) é objeto deste artigo. Nele, destacaremos dois aspectos, já aludidos anteriormente, bastante caros à estética pós-modernista, na medida em que, de certo modo, resumem satisfatoriamente seus impulsos vitais: o hibridismo e a simulação.

\section{A literatura pós-modernista de Luiz Ruffato: hibridismo e simulação}

Além de premiações diversas, traduções para outros idiomas e relevo nos cadernos de cultura de grandes jornais, Ruffato destacouse no cenário literário brasileiro com seu romance Eles eram muitos cavalos, publicado em 2001 e objeto de estudos e pesquisas acadêmicas que ressaltam, entre outros aspectos, a intercorrência de pequenas histórias relativamente independentes - o que motivaria, inclusive, uma discussão sobre o próprio estatuto de romance da obra -, apresentando um olhar que se voltava para as camadas mais baixas da população (vendedores ambulantes, assaltantes, bêbados, pedintes, o migrante nordestino), numa instigante mescla de gêneros discursivos (listas, anúncios de classificados, orações, cartas). Portanto, já nas características estruturais mais evidentes desse seu romance, percebe-se a presença de uma obsedante fragmentação narrativa, fato que, de início, sugere estarmos diante de uma obra em consonância com alguns pressupostos artísticos da estética pós-modernista. Com uma linguagem que procura 
aproximar determinado "estilo de vida" da população representada aos efeitos estilísticos em que o "enredo" é vazado, o romance adquire um inesperado tom de denúncia social. A linguagem desempenha, portanto, papel fundamental na construção da narrativa, cuidadosamente trabalhada na intenção de montar um painel social de uma cidade que abriga e exclui ao mesmo tempo, aproximando o modo de escrita do texto à linguagem cinematográfica. Trata-se, em suma, de uma espécie de mosaico de discursos, ${ }^{1}$ o que resulta num singular efeito de fragmentação narrativa (LAJOLO, 2004).

Esses são apenas alguns indícios do vínculo que a ficção de Ruffato estabelece com alguns dos princípios da pós-modernidade literária. Nesse diapasão, pode-se dizer que a presença de pelo menos duas categorias muito recorrentes em sua narrativa - hibridismo e simulação contribuem para a confirmação dessa assertiva, colocando Ruffato como um dos principais representantes, no Brasil, de traços estéticos próprios dessa tendência artística.

Em relação ao hibridismo, trata-se de uma categoria que, embora presente com mais frequência em dois de seus romances (Eles eram muitos cavalos e Flores artificiais), aparece de modo um tanto discreto em outras obras de sua autoria, como em (Os sobreviventes) (2000), em que se percebe um deliberado apego ao hibridismo discursivo (sobretudo em "Carta a uma jovem senhora"), com discursos que, ao se intercalarem, criam um efeito mais dinâmico, ao mesmo tempo que promovem uma variação de focos narrativos dentro de um mesmo conto. Esse processo de hibridização discursiva estender-se-á, posteriormente, para uma espécie de hibridização dos gêneros narrativos, como se verifica em Eles eram muitos cavalos. Esse, aliás, é um processo que, na ficção ruffatiana, se desdobra em vários outros modos de antrecambamento estético, como denotam as presenças da polifonia, em Vista parcial da noite (2006), ou do intercâmbio, em Estive em Lisboa e lembrei de você (2009).

Em Flores artificiais, essa categoria emerge de modo mais sistemático: lançando mão de uma escrita que, por mais de um motivo, apresenta recursos que podem ser creditados à expressão literária da pósmodernidade, a presença do hibridismo é verificada já na "apresentação" que o autor-narrador escreve, onde procura mesclar não apenas as

\footnotetext{
${ }^{1}$ Expressão utilizada pelo próprio autor, em palestra proferida em outubro de 2014, no auditório da Universidade Nove de Julho, em São Paulo.
} 
perspectivas verídica/objetiva e ficcional/subjetiva (recurso muito bem expresso, por exemplo, pelas notas de rodapé apensas ao texto principal), mas ainda os discursos popular e erudito, memorialístico e narrativo, traduzido e original, tudo transformado - nas próprias palavras do autornarrador, como a marcar, definitivamente, uma espécie de ambiguidade intrínseca da narratividade pós-modernista - em flores artificiais... A completar o quadro aqui esboçado, é relevante o fato de, no romance em tela, personagens viverem uma espécie de deslocamento identitário, personificando identidades dramaticamente híbridas, em que a ideia de descentramento acaba por promover ininterruptos deslocamentos estruturais, dando origem aos conceitos permeáveis e interagentes de descontinuidade e fragmentação, tudo isso plasmado numa representação estética que resulta na ruptura da expressão realista tout court.

A questão do hibridismo identitário já foi suficientemente discutida por Stuart Hall, para quem a contemporaneidade teria instituído novas identidades, caracterizadas, entre outros traços, pela fragmentação do sujeito pós-moderno, como resultado de mudanças estruturais e institucionais que tornam o processo de identificação instável e provisório e a identidade pouco fixa e permanente. Relacionando, nesse contexto, identidade e cultura, Stuart Hall afirma de modo peremptório:

[...] em toda parte, estão emergindo identidades culturais que não são fixas, mas que estão suspensas, em transição, entre diferentes posições; que retiram seus recursos, ao mesmo tempo, de diferentes tradições culturais; e que são o produto desses complicados cruzamentos e misturas culturais que são cada vez mais comuns num mundo globalizado. (HALL, 2005, p. 88)

O indivíduo contemporâneo seria, assim, resultado mediato de uma fratura no "núcleo estável do eu" (HALL, 2000, p. 108), tornando as identidades não unificadas e fragmentadas, fenômeno especialmente verificável nas chamadas situações de diáspora (HALL, 2003).

Em Flores artificiais, esse fenômeno é facilmente observado na figura da personagem Robert Clark (aliás, Bobby), que assume, já na primeira narrativa, uma identidade híbrida: estudante, mercenário, comerciante, militar, químico, proprietário, vagabundo, foi um pouco de tudo, para, no fim, morrer solitário, quase como indigente, restando-lhe apenas o nome escrito numa cruz apodrecida, condição que nos remete diretamente à afirmação de Hall (2005, p. 13), segundo a qual "o sujeito assume identidades diferentes em diferentes momentos, identidades que 
não são unificadas ao redor de um 'eu' coerente”. A questão da identidade híbrida, contudo, presente na constituição de personagens, disseminase ao longo de todo o livro, em particular em alguns relatos, como no caso de "O presente absoluto", em que se percebem não apenas uma multiplicidade de identidades, assumidas ao longo do relato por seus personagens, como um fato dado, mas sobretudo a transformação de uma identidade em outra(s), isto é, como processo: "Eu já não era uma mulher que carrega nome e sobrenome, professora aposentada, casada, mãe de dois filhos, francesa, mas um corpo mergulhado num instante único", afirma a personagem da narrativa, completando o quadro: "Quem voltou a Paris no dia seguinte não era a mesma pessoa, apesar de o passaporte insistir que sim..." (RUFFATO, 2014, p. 57).

Desse modo, pode-se dizer que o hibridismo identitário, nas narrativas analisadas, assume feição de uma identidade in progress, ou, para usar um termo um tanto marcado, de uma identidade imaginária: é o caso da narrativa intitulada "El gordo", história de uma personagem obsessiva pela busca de seu pai, homem cuja identidade é "imaginada" por todos que a ele se referem: pai de família, fugitivo da/perseguido pela ditadura, rompecorazones hollywoodiano, marido amoroso, bêbado inveterado, pelotudo de mierda... todas as identidades imaginadas cabem na figura de Seu Martins, cujo nome, aliás, só conhecemos no final da história. Essa quase anti-identidade parece passar, hereditariamente, para o próprio filho - igualmente sem nome, sendo mais conhecido por El Gordo, o brasileiro, talvez El Flaco... -, que, embora bem conhecido, guarda consigo o segredo indevassável do paradeiro do pai. Esse "fenômeno" identitário está presente, também, em "Comer sushi em Beirute", em que o narrador é servido, logo no começo da história, por uma garçonete "talvez tailandesa", "tailandesa, talvez vietnamita", "vietnamita, ou birmanira", "cambojana talvez", "chinesa talvez", "laosiana talvez", "malaia talvez"... Não espanta essa situação de desidentidade, uma vez que outras personagens da mesma narrativa (como Marcelo Barresi) se autoclassificam dizendo: "sou argentino... ou fui... um dia" (RUFFATO, 2014, p. 111).

Contudo, não são apenas as identidades que são múltiplas e, na concepção de Stuart Hall (2005), híbridas: os espaços também o são, uma vez que parecem se multiplicar ad infinitum, reproduzindo-se, diferenciando-se, articulando-se e desarticulando-se como se fossem parte de um grande todo, de um extenso mundo geograficamente (des) 
identificado. Mais do que espaços, são, nesse sentido, espécies de não lugares, na acepção que Marc Augé (2010) confere a uma das marcas do que define como supermodernidade. Assim, suas narrativas espalhamse pelas mais distintas latitudes, não apenas adquirindo um caráter "planetário", mas, também, assinalando que o mundo contemporâneo se "globaliza" tanto no plano da materialidade quanto no da subjetividade.

Afirmações similares podem ser feitas em relação à categoria de simulação, conceito estudado com afinco, entre outros autores, por Jean Baudrillard, segundo o qual a realidade contemporânea estaria marcada por sua perseverante presença:

[...] hoje a abstração já não é a do mapa, do duplo, do espelho ou do conceito. A simulação já não é a simulação de um território, de um ser referencial, de uma substância. É a geração pelos modelos de um real sem origem nem realidade: hiper-real. (BAUDRILLARD, 1991$, p. 8$)$

Assim, para o pensador francês, muito de nossa realidade adquire uma representação da verdade que é exorbitante, assinalando o que chama de apogeu do simulacro (BAUDRILLARD, 1986), fenômeno que, porventura, atinge sua maior concreção nas imagens que povoam as telas do mundo virtual, constituindo, agora, o que denomina a maldição do simulacro (BAUDRILLARD, 2005).

Flores artificiais, a propósito, é, igualmente, um termo bastante apropriado para ilustrar, metaforicamente, a ideia do simulacro: o "verdadeiro" valor e sentido das coisas e dos seres não reside no que é, mas, antes, no que parece ser, instaurando assim um mundo em que artifício e simulação se equivalem. Com efeito, tudo ou quase tudo no livro parece fazer parte de um incomensurável simulacro - do sugestivo título da narrativa (que já apresenta, in germine, a ideia de falsa verdade) à escolha do gênero (narrativa memorialística, contos, romance?), da questão autoral (Ruffato ou Finório?) à da identidade da narrativa (Flores artificiais ou Viagens à terra alheia?), da epígrafe (de Iacyr Anderson Freitas ou de Luís de Camões?) à dedicatória (teria Ruffato dedicado o livro a ele mesmo, o que já sugere um simulacro "atípico", ou o livro, na "verdade" é oferecido a Helena Terra?). Tudo, no final das contas, não passa, como sugerimos antes, de uma imensa simulação.

$\mathrm{O}$ autor, num típico exercício de artifício narrativo, testa, frequentemente, os limites entre ficção e realidade, entre verdade e 
fantasia: é, por exemplo, o que afirma logo no início da narrativa - que, não por mero acaso, classifica de história inverossímil -, quando diz, alertando o leitor: "essa história, por ser real, soará talvez fantasiosa" (RUFFATO, 2014, p. 21). Nesse mesmo sentido, prefere dizer tratar-se de um improvável "arremedo de biografia", escrita de maneira "que já não distingue memória e imaginação" (RUFFATO, 2014, p. 24). É exatamente esse discurso fragmentário e contraditório, nas palavras do próprio narrador, em que não se distingue o real do ficcional, que aqui buscamos classificar como simulacro, inscrevendo-se nos limites da estética pós-modernista.

Outro traço estilístico que podemos creditar - embora não exclusivamente - à estética pós-modernista e, em especial, ao artifício da simulação, é a mise en abyme: empregada com relativa insistência por autores modernos e contemporâneos (STAROBINSKI, 2014). Trata-se de um recurso de espelhamento/reprodução da realidade que, consequentemente, leva à sua dissimulação. No capítulo intitulado "Uma história inverossímil", no mesmo Flores artificiais, ela está presente não apenas enquanto intencionalidade - consciente ou inconsciente do narrador (afinal, num claro esforço de reconstituição da história narrada, ele assume escrever lembranças de lembranças, num evidente jogo especular) -, mas também na própria construção desse narrador - personagem que é, num processo de espelhamento sem fim, Robert Clark/Bobby (personagem biografado), refletido em Dório Finetto (personagem memorialista), que por sua vez é travestido pelo narrador do romance, na voz autoral de Luiz Ruffato (e, nesse último caso, não se está confundindo, como sói acontecer, narrador e autor, já que Ruffato assume a condição de uma espécie de tradutor dos manuscritos de Finetto). É esse encadeamento de vozes discursivas, apresentadas em sequência especular (Robert Clark - Bobby - Finetto - Ruffato) que confere à narrativa, por meio do recurso da mise en abyme, um feitio de narrativa pós-modernista.

Mas a arquitetura do romance não para por aí, levando ao limite o recurso citado, na medida em que também na esfera discursiva - de gêneros do discurso, para sermos mais exatos - a reprodução especular se faz presente: afinal, esse arremedo de biografia, essas lembranças de lembranças, essa recomposição de uma história de vida apresentase, agora num caminho inverso, como o romance da memória de uma biografia. Vigora, assim, definitivamente, ao lado do hibridismo, o império da simulação... 


\section{Conclusão}

A ocorrência de uma estrutura híbrida e de recursos estilísticos direta ou indiretamente relacionados à ideia de simulacro parece ser marca constante da produção ficcional de Luiz Ruffato, não apenas no romance aqui analisado, mas em boa parte de sua prosa de ficção, em especial no célebre Eles eram muitos cavalos, em que a mescla de gêneros pouco comuns ao romance "tradicional" - como a hagiografia, a receita de bolo, a previsão do tempo, os anúncios de jornal etc. -, unida à forma fragmentária da composição narrativa parecem ser recursos estéticos recorrentes. Tudo isso, se não o coloca como um típico autor da pós-modernidade literária brasileira, ao menos aponta em suas narrativas alguns evidentes percursos pós-modernistas, como procuramos sugerir desde o início.

\section{Referências}

AUGÉ, M. Não lugares: introdução a uma antropologia da supermodernidade. Campinas: Papirus, 2010.

BAUDRILLARD, J. A transparência do mal: ensaios sobre os fenômenos extremos. São Paulo: Papirus, 1990.

BAUDRILLARD, J. As estratégias fatais. Rio de Janeiro: Rocco, 1986. BAUDRILLARD, J. Simulacros e simulação. Lisboa: Relógio d'Água, 1991.

BAUDRILLARD, J. Tela total: mito-ironias do virtual e da imagem. Porto Alegre: Sulina, 2005.

BENJAMIN, W. Magia e técnica, arte e política: ensaios sobre literatura e história da cultura. São Paulo: Brasiliense, 1986.

CANCLINI, N. G. A sociedade sem relato: antropologia e estética da iminência. São Paulo: Edusp, 2012.

CARNEIRO, F. No país do presente: ficção brasileira no início do século XXI. Rio de Janeiro: Rocco, 2005.

HALL, S. A identidade cultural na pós-modernidade. Rio de Janeiro: DP\&A, 2005.

HALL, S. Da diáspora: identidades e mediações culturais. Belo Horizonte: UFMG; Brasília: UNESCO, 2003. 
HALL, S. Quem precisa da identidade? In: SILVA, T. T. da (Org.). Identidade e diferença: a perspectiva dos Estudos Culturais. Petrópolis: Vozes, 2000. p. 103-133.

HOBSBAWM, E. Era dos extremos: o breve século XX (1914-1991). São Paulo: Companhia das Letras, 2001.

HUTCHEON, L. Poética do pós-modernismo: história, teoria, ficção. Rio de Janeiro: Imago, 1991.

JAMESON, F. A cultura do dinheiro: ensaios sobre a globalização. Petrópolis: Vozes, 2002.

LAJOLO, M. Como e por que ler o romance brasileiro. Rio de Janeiro: Objetiva, 2004.

LUCAS, F. Vanguarda, história e ideologia da literatura. São Paulo: Ícone, 1985.

PINTO, M. da C. Literatura brasileira hoje. São Paulo: Publifolha, 2004.

PROENÇA FILHO, D. Pós-modernismo e literatura. São Paulo: Ática, 1995.

RUFFATO, L. (Os sobreviventes). São Paulo: Boitempo, 2000.

RUFFATO, L. Eles eram muitos cavalos. São Paulo: Boitempo, 2001.

RUFFATO, L. Estive em Lisboa e lembrei de você. São Paulo: Companhia das Letras, 2009.

RUFFATO, L. Flores artificiais. São Paulo: Companhia das Letras, 2014.

RUFFATO, L. Vista parcial da noite. Rio de Janeiro: Record, 2006. (Inferno Provisório, 3).

SANTOS, J. F. dos. O que é pós-moderno. São Paulo: Brasiliense, 2006.

STAROBINSKI, J. A melancolia diante do espelho: três leituras de Baudelaire. São Paulo: Editora 34, 2014.

SÜSSEKIND, F. Literatura e vida literária: polêmicas, diários e retratos. Belo Horizonte: UFMG, 2004.

Recebido em: 22 de fevereiro de 2017.

Aprovado em: 9 de julho de 2017. 